\title{
Post-stroke depression and the aging brain
}

\author{
Gabriel R Cojocaru', Aurel Popa-Wagner ${ }^{3}$, Elena C Stanciulescu, Loredana Babadan ${ }^{1}$ and Ana-Maria Buga ${ }^{1 *}$
}

\begin{abstract}
Ageing is associated with changes in the function of various organ systems. Changes in the cardiovascular system affect both directly and indirectly the function in a variety of organs, including the brain, with consequent neurological (motor and sensory performance) and cognitive impairments, as well as leading to the development of various psychiatric diseases. Post-stroke depression (PSD) is among the most frequent neuropsychiatric consequences of cerebral ischemia. This review discusses several animal models used for the study of PSD and summarizes recent findings in the genomic profile of the ageing brain, which are associated with age-related disorders in the elderly. Since stroke and depression are diseases with increased incidence in the elderly, great clinical benefit may especially accrue from deciphering and targeting basic mechanisms underlying PSD. Finally, we discuss the relationship between ageing, circadian rhythmicity and PSD.
\end{abstract}

Keywords: Aging, Stroke, Post stroke depression, Gene profiling

\section{Review \\ Background}

Depression in stroke survivors is of utmost clinical relevance. It often takes a chronic course and is associated with increased morbidity, mortality and a poorer functional outcome. Despite the fact that a high proportion of stroke patients develop mood symptoms, the pathomechanisms underlying the development of poststroke depression (PSD) have so far received little attention from the field of neurobiology. Relevant animal models have only sparsely been investigated. This research gap becomes even more regrettable if one considers the growing body of clinical evidence indicating a beneficial effect of antidepressants and especially of selective serotonin reuptake inhibitors (SSRIs), on postischemic outcome. Since old age as such is also associated with an enhanced susceptibility to stroke along with a poorer recovery from brain injury, it deserves to be investigated as a key modulatory factor. If we cannot prevent stroke, we shall try to alleviate its long-term consequences. In particular, great clinical benefit may accrue from deciphering and targeting basic mechanisms underlying chronic PSD in aged animals. So far, the majority of experimental stroke studies have concentrated

\footnotetext{
* Correspondence: anamaria.buga@webmail.umfcv.ro

'Department of Functional Sciences, Center of Clinical and Experimental Medicine, University of Medicine and Pharmacy of Craiova, Petru Rares str., no 2, Craiova 200349, Romania

Full list of author information is available at the end of the article
}

heavily on acute stroke outcome, which, after all, represents only a snapshot of a complex sequence of events. This limitation may have majorly contributed to the conspicuous discrepancy between laboratory and clinical findings that has been a recurrent theme in stroke research in recent years ('translational road block').

\section{Post-stroke depression \& aging}

Age is the most important risk factor for cerebral ischemia and recovery after stroke is significantly influenced by age. A large spectrum of factors, like genetic, epigenetic or environmental factors, contributes to the aging phenotype. One prospective population-based study estimates that the incidence of mental illnesses like anxiety, anhedonia and depression after stroke is about 35\% among the stroke survivals and the rate of disabilities and cognitive defficits increasesed with age [1]. Depression after stroke runs a chronic course and is related to increased morbidity and mortality [2-9]. More than that, depression symptoms may even worsen during the chronic phase after stroke $[1,9,10]$. Anxiety is associated with physical disability may contribute to the development of PSD. However, the higher prevalence of symptoms of depression in stroke patients as compared with other patients with similar degree of disability can be a good argument against psychological explanations of PSD $[9,11]$.

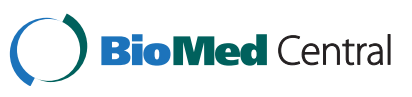

(c) 2013 Cojocaru et al.; licensee BioMed Central Ltd. This is an Open Access article distributed under the terms of the Creative Commons Attribution License (http://creativecommons.org/licenses/by/2.0), which permits unrestricted use, distribution, and reproduction in any medium, provided the original work is properly cited. 
Comorbidities such as hypertension, obesity, diabetes, dyslipidemia and systemic inflammation increase the probability of silent strokes. Microvascular changes and silent strokes in vulnerable regions may lead to the so-called 'vascular depression' $[12,13]$. Several genes such as the genes encoding angiotensin-converting enzyme (ACE), protein kinase $\mathrm{C}(\mathrm{PRKCH})$, apolipoprotein (a) [apo (a)] and lipoprotein(a) $[\mathrm{Lp}(\mathrm{a})]$ may play an important role in the ethiology of vascular depression [14-16].

\section{Animal models of stroke and post-stroke depression: role of aging}

To study the biological processes underlying functional recovery after stroke in ageing brain a variety of physiologically complex organisms like rats, mice or nonhuman primates have been used. But, the rat model is by far the most used in stroke research due to the similarities with human brain neurovascular branching and the available behavioural outcome measurements. The most commonly used ischemic stroke models in rodents are: middle cerebral artery occlusion (MCAO) for transient or permanent occlusion and endothelin-1 model for transient occlusion. To study the rehabilitation process after cerebral ischemia is important to choose an appropriate animal model and to optimize this model. Epidemiological studies reveal that human ischemic stroke occurs frequently in late middle age (50-70 years) than at older ages (over 70 years) $[17,18]$. Therefore it is highly recommened to use middle aged rats for stroke studies. Consequently, animal studies conducted on aged (18 month-old) rats demonstrated that there was a decline in the ability of aged brain to sustain plasticity-related process and poorer neurological functional recovery after ischemia in older rats than in younger animals [19-25]. Other research studies that used middle-aged rats (12-18-month) showed that more expressed alteration have been found compared with young animals at structural and functional levels [24,26-29]. Interestingly, there are significant differences in brain response to injury in old subjects compared with young ones. Therefore extrapolating the results from young animals to aged humans could lead to erroneous conclusions.

The aged rodent model offers a useful tool to investigate mechanisms and treatments of ischemic stroke in preclinical studies. The models in aged animals have to be designed to create a reproducible lesion which mimics the human pathophysiological changes, to be minimally invasive, and to allow objective measurement and analysis of tissue damage after cerebral ischemia. In agreement with this concept, previous studies have shown that mortality in post-stroke aged rate is higher compared with young animals, most likely because the lesion appears on a background already altered by senescence itself. On the physiological level, functional and cognitive decline are closely connected to morphological changes of the brain during the aging process.

Imaging techniques, positron emission tomography (PET) or magnetic resonance imaging (MRI), have revealed a significant reduction in the cerebral blood flow (CBF), mostly in the cortex, which may be linked to these morphological changes in the aged brain. Overall, cerebrovascular dysfunction associated with metabolic changes due to senescence increases the vulnerability of brain to ischemic-hypoxic injuries like stroke. Cerebral ischemia occurs frequently in elderly, and increased vulnerability of the aged brain leads to unfavorable recovery of physical and cognitive functions. Although imaging techniques have already been used in numerous studies in animal models of stroke, few groups have applied MRI methods to characterize and monitor the dynamics of ischemic lesions in aged ischemic animals [30-33].

The aged brain displays a higher susceptibility to hypoxia compared with young animals in the acute phase of stroke [27,32]. On MRI images, aged ischemic rats displayed more severe lesions, which were with similar localizations, but higher incidence and more rapid appearance than in the young rats $[30,31]$. With the use of functional magnetic resonance imaging (fMRI) it was demonstrated that patterns of bihemispheric reorganization (increase of the fMRI response in the ipsilateral somatosensory cortex and bilateral thalamic activation) after permanent MCAO in aged rats were the same as in young animals, although the overall time course of recovery in aged rats was more prolonged than that in young rats [32]. Studies using electrophysiological techniques, and in particular electroencephalography (EEG), in ischemic aged animals are mostly lacking. EEG has been used as a tool for verifying the success of the occlusion [30], for identifying the effect of hypothermia on neuronal functions [34].

\section{Animal models of depression}

Modelling psychiatric conditions like depression after stroke in animal models is not trivial. The psychological evaluation by clinicians is not available in animal models and most of these models are validated only by behavioural observation or by behavioural changes in response to treatment. Therefore instead of trying to fully replicate all the human symptoms of depression, we shall try to uncover the underlying signalling pathways in animal models of mood disorders that strongly meet the validating criteria including strong endophenotype similarities, comparable etiology and the same treatment [35-37]. To this end, various behavioral tests have been proposed to investigate some of the central aspects of human-like depression in rodents. For example, the forced swim test in which rodends are exposed to water stress and are 
forced to swim $[9,38]$ or the tail suspension test (animals are suspended horizontaly by tail for a short period of time) $[39,40]$ are commonly used as behavioral paradigms that quantify behavioral changes in a stressful situation (behavioral despair). These tests measure the immobility of depressed animals in despair situation and have been pharmacologically validated using antidepressant drugs that are already in human use $[41,42]$.

Anhedonia (the loss of interest) is an important symptom of depression that can be measured in rodents by a decrease in sucrose consumption. Rodents normally prefer sweet fluids like glucose or sucrose instead of water. Quantifying consumption of sucrose is the most used endpoint for assessing motivation and affective state in rodends after repeated chronic stress exposure. Also, this test can quantify reversal of this effects after antidepressive drugs administration [9,43-45]. Some studies report decreased sucrose consumption at 2 weeks after transient focal ischemia in mice, suggesting a hedonic deficit in MCAO animals [40,44-46].

Exposure to unpredictable chronic mild stress (CMS) associated with isolation of animals after ischemia is another way to study experimental PSD. It has been shown that after cerebral ischemia, animals show decreased locomotor activity in the open field test and decreased sucrose consumption when exposed to CMS paradigm for 18 days after surgery [9].

\section{Biology of post-stroke depression: role of ageing}

The high incidence rates of stroke patients that develop mood symptoms (between 20-50\%) justify the effort of researchers to go further into the neurobiological mechanisms of disease [47-49]. Many studies suggest that PSD is a consequence of brain lesions that are associated with disruptions in synaptic transmission, changes in signalling pathways and increased biological vulnerability of the post-stroke aged brain [50-53]. Some other studies reported that PSD is a consequence of specific brain lesions and differences in the incidence of depression between different brain areas have been reported [54,55]. In this context, left hemispheric cortical stroke, mainly frontal lesions has been reported to be linked with an increased risk for depression. However, there are still controversial points of view regarding the relationship between the area of the brain affected by stroke and incidence of PSD.

On the other hand, the prevalence of the memory cognitive impairment like dementia or depression is higher in elderly after stroke. One question is that if cerebral ischemia causes secondary degenerative changes in the brain or that ongoing degenerative changes will be simply aggravated by stroke. From a psychological perspective, the severity of PSD is determined not only by individual differences in emotional reactions to disease (e.g. negative attitude) but also, by the severity of physical and cognitive impairment and by the absence of familial and social support [56].

Many studies suggest that post-stroke vulnerability of the brain can induce PSD and PSD is associated with reduced recovery after stroke in stroke survival patients. However, until now there is no clear evidence to support the etiological mechanisms of PSD, which seems to be a multifactorial disease of the ageing brain.

One important issue is how to distinguish the depressive symptoms in patients in the early stages after stroke from cognitive impairments due to neurodegeneration prior to stroke and the ageing process itself. Some longitudinal studies on post stroke patients showed that chronic PSD is highly predictable if post stroke patients are experiencing depression symptoms between 6 month and 1 year after brain injury [57,58].

Most of these studies analyzed the risk of post-stroke depression in relatively young people's that have a job and are not living alone. Also, in these studies, patients with language problems like aphasia or neurodegenerative disease like dementia where excluded. However, since stroke occur frequently in people over 65 , studies on older patients with stroke and other age-related comorbidities should be more relevant than studies on young people. In this light, multi-therapeutic approach of PSD in the recovery phase that include genetic, social and psychological aspects have the greatest potential for improving post-stroke recovery and the quality of life in elderly post-stroke survivors.

\section{Neurogenesis, cognitive decline \& post-stroke depression}

Age-related cognitive decline is often associated with decreassed hippocampal neurogenesis and depression, but relatively little is known about the biological significance of neurogenesis in the ageing mammalian brain for the development of depression. Two major hypotheses have driven most of the studies on hippocampal neurogenesis, namely (i) it plays a pivotal role in hippocampus-dependent learning and memory $[59,60]$ and, (ii) it protects against anxiety and depression $[61,62]$. However, mechanisms underlying the precise role of neurogenesis remains controversial. For example, genetic ablation of the cell cycle regulatory protein cyclin D2 that results in virtual absence of newly born neurons in the adult brain does not lead, surprisingly, to appreciable learning and memory deficits [63-65]. Similarly, the involvement of hippocampal neurogenesis in depression and in the efficacy of antidepressive treatments is also not fully understood.

One possible molecular mechanism underlying agerelated depression and decreased neurogenesis can be due to an increased level of the dickkopf 1 homolog Xenopus laevis (Dkk1), that decreases Wnt signaling 
pathways and has been associated with a decline in hippocampal neurogenesis [66].

Other mechanisms that can be involved in neurorecovery are related to neurotrophin signaling pathway. Neurotrophins are important players in early neuronal gene response to injuries. The neutrophin-signaling pathway activates extracellular-signal-regulated kinases (ERK) pathway and nuclear transcription. Meier and colleagues demonstrated that hippocampal neuronal culture treated with brain derived neurotrophic factor (BDNF) promotes axonal guidance, modulate the synaptic function, stimulate neurite branching and is antagonized by Ephrin (Eph) signaling [67,68]. Also, decreased levels of BDNF, a key factor in the regulation of hippocampal neurogenesis, seems to be associated with depression and neurodegenerative disorders, but the mechanisms underlying this association are still unknown [69]. Finally, Cui and colleagues reported that the combination therapy, simvastatin with human umbilical blood cells, increased endogenous neurogenesis and cell plasticity in the ischemic area via BDNF/TrkB signaling pathway [70].

Even less is known about the relationship between PSD and neurogenesis in the elderly. The level of hippocampal neurogenesis has been shown to decrease steadily with aging [71]. Since aged animals might be both more prone to develop a depressive phenotype [72] and the aged brain is more sensitive to the deleterious effects of ischemia [27,73], one could expect more severe PSD symptoms in aged animals. Such an experimental model of PSD, taking into account these influences of aging, should be highly clinically relevant.

Depressive behavior in ischemic rats was accompanied by reduced ischemia-evoked hippocampal neurogenesis and this effect was reversed by citalopram administration [9]. Using pharmacological interventions, the involvement of serotonergic neurotransmission was then further corroborated $[74,75]$. One study in non-human primates, proved that the repeated separation stress is associated with depression-like behavior (anhedonia) and reduced hippocampal neurogenesis [76]. Also, recovery from stroke was shown to be associated with growth factor-induced neurogenesis in SVZ as well as exercise-induced neurogenesis in SGZ [77,78]. Similarly, therapy with granulocyte colony stimulating factor (G-CSF) enhanced neurogenesis, improved working memory in the radial-arm maze test and in consequence the survival capacity and functional outcome after stroke [27]. However, these findings need further confirmation along with a clear demonstration of functional significance in human diseases. We should take into account that other age-associated comorbidities like hypertension or obesity can negatively affect the hippocampal functions.

\section{Genome profiling of mood disorders in the elderly}

Transcriptional profiling is a usefull tool to identify genetic pathways associated with mood symptoms in the elderly. Most studies reporting the use of gene expression profiling to investigate rodent models of depression focused on stress models and did not supply direct evidence for a specific genomic signature in PSD depression. Kang and collegues identified some synaptic-function-related genes that are connected with decreased in number and function of synapse in a rat model of major depression. These genes included: calmodulin 2 (Calm2), synapsin 1 (Syn1), tubulin beta 4 (Tubb4) a member of ras-related protein Rab-4B (Rab4b). Also, increased expression of the transcriptional repressor erythroid transcription factor/ GATA-binding factor 1 (GATA1) is responsible for downregulation of these synaptic-function-related genes [79].

In another study, genes related to human major depression like serotonin receptor 2a gene (Htr2a), neurotrophic tyrosine kinase receptor type 2 and 3 genes (Ntrk2 and Ntrk3), corticotropin releasing hormone receptor 1 (Crhr1) and corticotropin releasing hormone $(\mathrm{Crh})$ were differentially expressed in three animal models of depression: acute treatment with reserpine, olfactory bulbectomy and chronic treatment with corticosterone [9]. In addition, two new genes, complement component 3 and fatty acid-binding protein 7 , have recently been described $[80,81]$. Similarly, then polymorphism of 5- hydroxytryptamine 2 a receptor (Htr2a), a postsynaptic target for serotonin signaling, has been implicated in neuropsychiatric disorders [82]. In addition, increased functional activity of the amygdala in response to negative stimuli appears to be a moodcongruent phenomenon that is likely moderated by the 5-HT transporter gene (Slc6a4) promoter polymorphism (5-Httlpr) [9]. Lohon and colleagues showed significant gene-gene interaction between Slc6a4 and 5-Httlpr/ rs25531 in general anxiety disorder [83].

An oligodendrocyte/myelin-associated genes, 2,3'-cyclic nucleotide 3'-phosphodiesterase (CNP) was identified to be associated with catatonia-depression syndrom in the elderly. Using aged heterozygous null mutant mice model of spontaneous catatonia, Hagemeyer and collegues showed that the reduced expression of CNP is accelerated by aging and is associated with neurodegenerative changes in the elderly [84].

\section{Gene expression \& mood disorders in elderly}

In previous studies we have identified a number of genes that are involved in neuropathic syndrome and PSD signaling pathways in aged brain (e.g. 5- hydroxytryptamine 2a receptor - Htr2b, prepronociceptin - Pnoc). These genes could be pharmacological targets in a multimodal therapy of stroke and stroke related diseases [16]. 
Using fosB-Null mice, Yutsudo and colleagues reported impaired neurogenesis and depressive behavior in fosB-Null mice [85]. Intriguingly, FBJ murine osteosarcoma viral oncogene homolog B (fosB) expression has been associated with stem cell and neural progenitor cells proliferation after cerebral ischemia in mammalian central nervous system [86,87]. These studies suggest the genomic signature is crucial for the evolution of disease, but is the "genomic reprogramming" a future powerful tool that can be exploited to improve the neurorecovery after stroke? Some studies identified the ciliary neurotrophic factor (Cntf) receptor as a key molecular factor that can inhibit neurogenesis in the type B stem cells, but the mechanism is still unknown
$[88,89]$. Cntf is expressed only in central nervous system where modulates the normal neurogenesis. Stimulation of this factor can be a novel pharmaceutical strategy for neurogenesis-dependent diseases like stroke and PSD [89]. Table 1 summarize all the specific genes involved in the ethiology of depression and post-stroke depression.

\section{Mood disorders, circadian rhythmicity and aging}

Disturbances in the circadian rhythm may have dramatic effects on our health. Changes in biological rhythm disturbances precede and parallel the occurrence of mood episodes of illness and have been proposed to play a pathogenetic role in major depression and mania [105-110]. The controlled administration of stimuli that

Table 1 Specific genes involved in the ethiology of depression and post-stroke depression.

\begin{tabular}{|c|c|c|c|c|c|c|}
\hline Gene symbol & Description & Gene Function & $\begin{array}{l}\text { Gene } \\
\text { expression }\end{array}$ & Disease & $\begin{array}{l}\text { Human/animal } \\
\text { data }\end{array}$ & Ref. \\
\hline \multicolumn{7}{|l|}{ Depression } \\
\hline GSK- $\beta$ & Synthase-kinase-3 $\beta$ & $\begin{array}{l}\text { Central regulator of } \\
\text { circadian rhythms }\end{array}$ & Up & Depression & Transgenic mice & {$[90]$} \\
\hline CLOCK & $\begin{array}{l}\text { Circadian Locomotor Output } \\
\text { Cycles Kaput }\end{array}$ & $\begin{array}{l}\text { Central regulator of } \\
\text { circadian rhythms }\end{array}$ & SNP & $\begin{array}{l}\text { DepressionBipolar } \\
\text { disorders }\end{array}$ & Transgenic mice & {$[91]$} \\
\hline $\begin{array}{l}\text { ARNTL } \\
(B M A L 1)\end{array}$ & $\begin{array}{l}\text { Aryl hydrocarbon receptor } \\
\text { nuclear translocator-like }\end{array}$ & PER1 activator & SNP & Sleep disorders & Human sample, & {$[92,93]$} \\
\hline NPAS2 & $\begin{array}{l}\text { Neuronal PAS domain } \\
\text { protein } 2\end{array}$ & $\begin{array}{l}\text { Part of a molecular } \\
\text { clock }\end{array}$ & SNP & Mood disorders & Human sample, & {$[92,94]$} \\
\hline \multicolumn{7}{|c|}{ Synapse-related genes in depression } \\
\hline CALM2 & Calmodulin 2 & Cytokinesis regulator & Down & Depression & Animal model & {$[89]$} \\
\hline SYN1 & Synuclein 1 & $\begin{array}{l}\text { Synaptogenesis and } \\
\text { neurotransmitter release }\end{array}$ & Down & Depression & Animal model & {$[89,95]$} \\
\hline \multicolumn{7}{|c|}{ Depression in the elderly } \\
\hline PER2 & Period circadian clock 2 & $\begin{array}{l}\text { Central regulator of } \\
\text { circadian rhythms }\end{array}$ & $\begin{array}{l}\text { SNP } \\
\text { Up }\end{array}$ & $\begin{array}{l}\text { Sleep disorders } \\
\text { Ageing brain }\end{array}$ & $\begin{array}{l}\text { Human sample Animal } \\
\text { model of ageing }\end{array}$ & {$[92,93,96]$} \\
\hline PER3 & Period circadian clock 3 & $\begin{array}{l}\text { Central regulator of } \\
\text { circadian rhythms }\end{array}$ & SNP & $\begin{array}{l}\text { Sleep disorders, } \\
\text { Aged brain }\end{array}$ & Human sample & {$[93,97-99]$} \\
\hline 5-HTTLPR & Serotonin transporter promotor & Serotonin transporter & SNP & $\begin{array}{l}\text { Depression in } \\
\text { the elderly }\end{array}$ & Human sample & {$[100]$} \\
\hline TUBB4 & Tubulin, Beta 4A Class IVa & $\begin{array}{l}\text { Constituent of } \\
\text { microtubules }\end{array}$ & Down & Depression Ageing & Animal model & {$[89,101]$} \\
\hline \multicolumn{7}{|c|}{ Depression and recovery after stroke } \\
\hline BDNF & $\begin{array}{l}\text { Human brain-derived } \\
\text { neurotrophic factor (BDNF) }\end{array}$ & $\begin{array}{l}\text { Growth factor in } \\
\text { the brain }\end{array}$ & SNP & $\begin{array}{l}\text { Depression } \\
\text { Recovery after injury }\end{array}$ & $\begin{array}{l}\text { Human sample, } \\
\text { Animal model }\end{array}$ & {$[102,103]$} \\
\hline SLC6A4 & $\begin{array}{l}\text { Solute Carrier Family } 6 \\
\text { Member } 4\end{array}$ & $\begin{array}{l}\text { Membrane protein } \\
\text { transporter of serotonin }\end{array}$ & SNP & $\begin{array}{l}\text { Depression Stroke } \\
\text { recovery }\end{array}$ & Human sample & {$[9,83]$} \\
\hline GATA1 & GATA Binding Protein 1 & Transcription factors & Upregulation & $\begin{array}{l}\text { Depression Stroke } \\
\text { recovery }\end{array}$ & Animal model & {$[104]$} \\
\hline HTR2B & $\begin{array}{l}\text { 5-Hydroxytryptamine } \\
\text { (Serotonin) Receptor 2B }\end{array}$ & Serotonin receptor & Upregulation & $\begin{array}{l}\text { Poststroke } \\
\text { depression in } \\
\text { elderly }\end{array}$ & Animal model & {$[16,34]$} \\
\hline PNOC & Prepronociceptin & Opioid receptor & Downregulation & $\begin{array}{l}\text { Poststroke } \\
\text { depression in } \\
\text { elderly }\end{array}$ & Animal model & {$[16,34]$} \\
\hline
\end{tabular}


can directly act on the clock, namely light and manipulations of the sleep-wake rhythm, has established high efficacy in the treatment of mood episodes, also in drug resistant patients. Effects of Total Sleep Deprivation and Light Therapy on the phase of biological rhythms could be part of its mechanism of action.

To understand the therapeutic action of these mood stabilizing drugs as well as antidepressants, investigators have recently begun to examine their effects on intracellular signaling pathways that regulate clock gene expression. Yang and collegues [111] utilised an ex vivo approach to examine circadian rhythms in clock gene expression profiles in fibroblasts either obtained from bipolar disorder patients or healthy controls, and report that gene encoding for a basic helix-loop-PAS domain (bHLH-PAS domain) transcription factor (BMAL1), period circadian protein homolog 1 (PER1), period circadian protein homolog 1 (PER2), nuclear receptor subfamily 1 , group D, member 1 (REV-ERB- $\alpha$ ) and the clock controlled gene, D Site Of Albumin Promoter (Albumin D-Box) Binding Protein (DBP), all tended towards reduced amplitudes of circadian oscillation in bipolar disorder.

Assessing the impact of agomelatine on depressed bipolar patients [112], while measuring their circadian rhythms, may therefore help to further precise if it is through the restoration of circadian rhythms that agomelatine get treatment reponse (assessed by actimetry), and help to pinpoint which genes expression are being specifically modified (from fibroblasts). Diurnal rodents to decipher the relationship between circadian rhythms and depression. One of the major obstacles in the developent of appropriate models for circadian rhythm disturbances-related psychiatric diseases may arise from the fact that the standard animals used in neuropsychiatric research are nocturnal rodents. Despite of the extraordinary advancement in our understanding of the circadian clock mechanism, it is still unclear how are the temporal signals from the clock translated into activity patterns, and how do they differ in diurnal and nocturnal mammals.

Nevertheless, it is clear that some fundamental differences exist between nocturnal and diurnal mammals which may be crucial for the study of circadian rhythms related diseases [113-115]. For example much like humans, diurnal species are active when melatonin levels are low, while nocturnal mammals are active when melatonin levels are high. Another important component of the circadian system is the masking effect of light. Specifically, light increases activity in diurnal mammals (positive masking) and suppresses it in nocturnal ones (negative masking), while darkness acts in the opposite ways $[116,117]$. Therefore we suggest that using diurnal animals to decipher the molecular mechanisms underyling the relationship between circadian rhythms and affective behavior [118].
Circadian rhythms display an unregular pattern with aging manifested by alteration of sleep quality and cognitive performance $[119,120]$. Hermannn and Bassetti [121] showed that the alterations of the sleep-wake cycle like hypersomnia or excessive daytime sleepiness occur in $10 \%-50 \%$ of all stroke cases and are associated with negative long-therm clinical outcome. Also, Ramar and Surani [122] showed that the circadian rhythm disorders could increase the risk of stroke. But, if disturbances in the circadian rhythm are a risk factor or a consequence of ischemic stroke in the elderly remains to be clarified.

Some studies showed that one mechanism that contributes to increased risk of depression is the decrease in the synthesis of $\mathrm{N}$-acetylserotonin with ageing [123]. Since $\mathrm{N}$-acetylserotonin activates TrkB signaling pathway in a circadian fashion (higher in the night and lower during the day) via TrkB receptor, and has antidepressant effects [124] it has been hypothesized that disturbances in the circadian rhythms may cause psychiatric disorders. For example, Bunney and colleague showed that an altered circadian function and altered expression of the central circadian clock genes, BMAL1/CLOCK (Npas2) in mood disorders [125]. Also, Circadian Locomotor Output Cycles Kaput (CLOCK) genes are strongly involved in the circadian rhythm and these are closely related with external factors [126]. Therefore dysfunctions of circadian time regulatory mechanisms in the aged brain may underlie the etiology of PSD in the elderly. The effect of circadian rhythm on PSD outcome in the elderly is still an unexplored field.

\section{Therapy of post-stroke depression}

Norepinephrine (NE), serotonin (5-HT), and dopamine (DA) overlap in the brain and all three transmitters are implicated in the symptoms of depression Depressive symptoms may result from dysfunction of any or all of the monoamine neurotransmitter systems. The effects of NE, 5-HT and DA overlap in the brain and all three transmitters are implicated in the symptoms of depression. Because these monoamine transporters (MATs) are important regulators of the extracellular neurotransmitter concentration, mouse gene knockouts of serotonin transporter (SERT), the noradrenaline transporter (NAT) and also the dopamine transporter (DAT) located in the plasma membrane of corresponding neurons provide interesting models for possible effects of chronic antidepressant treatments. Inhibition of neurotransmitter reuptake by drugs acting at SERT, NET and/or DAT can produce antidepressant effects $[127,128]$.

The mechanism of PSD was suggested to involve multiple pathways, like immune activation, hypoxia, apoptosis and necrosis of neuronal or glial cells or hyperactivation of the hypothalamic-pituitary-adrenal axis. Many studies 
reported different therapeutic strategies designed to improve the PSD outcome. Of these, cortisol-lowering therapies and increases of neurotropic factors like BDNF were reported to be novel possible therapeutic strategy for PSD [129].

In addition, a growing body of evidence indicate a beneficial effect of antidepressants and especially of SSRIs on postischemic outcome [9]. Antidepressants may also exert direct actions on the brain, providing neuroprotection and promoting brain plasticity and neurogenesis.

Antidepressants treatment initiated soon after stroke in non-depressed post-stroke patients may prevent the later PSD but the time window of treatment remains to be optimized [130]. A number of studies have also reported beneficial effects of antidepressant pharmacotherapy on long-term functional outcome after stroke including activities of daily living as well as cognitive functioning [9,131-135]. Other in vivo and in vitro studies have shown that fluoxetine and paroxetine which are the most commonly prescribed antidepressants, prevented degeneration of nigrostriatal dopaminergic neurons. These drugs reversed the hypoactivation found in the primary motor cortex of patients [136] and the increased activation was correlated with improved performance after drug intake and repression of proinflammatory markers [9]. These results remain, however, to be validated in large clinical trials of stroke patients.

\section{Conclusions}

In conclusion, depression is the most frequent neuropsychiatric disease of brain ischemia, affecting up to $35 \%$ of all such patients. PSD is associated with negative outcome of functional recovery, cognition and social reintegration of stroke patients. During de past decade, significant efforts have been made to establish an efficient treatment of PSD in the elderly. So far, preclinical and translational research on PSD is largely lacking. The implementation and characterization of suitable animal models is clearly a major prerequisite for deeper insights into the biological basis of post-stroke mood disturbances and may also pave the way for the discovery of novel therapeutic targets. Nevertheless it is unlikely that monotherapies will provide a cure for PSD. Rather multitherapeutic strategies should be at the focus of future clinical trials conducted on PSD and mood disorders patients without cerebral ischemia that show the same clinical profile. In this light, future research is needed to identify the molecular mechanism of disease and to establish the pathways that are modulated by antidepressant drugs leading to a better cognitive recovery in the elderly patients.

\section{Competing interests}

The authors declare that they have no competing interests.

\section{Authors' contribution}

$A M B$ conducted the literature search and drafted the manuscript, GRC have made substantial contributions to conception and design, ECS and LB have made contributions to conception and design, APW participated in drafting the manuscript and provided critical revision of the manuscript. All authors read and approved the final manuscript.

\section{Acknowledgements}

The authors confirm that there are no conflicts of interest. Research was funded in part from a UEFISCDI partnership grant no 80/2012 and UEFISCDI FLARE2

\section{Author details}

${ }^{1}$ Department of Functional Sciences, Center of Clinical and Experimental Medicine, University of Medicine and Pharmacy of Craiova, Petru Rares str., no 2, Craiova 200349, Romania. ${ }^{2}$ Faculty of Pharmacy, Chair of Biochemistry, University of Medicine and Pharmacy of Craiova, Craiova 200349, Romania.

${ }^{3}$ Department of Psychiatry, University of Medicine Rostock, Rostock, Germany.

Received: 13 March 2013 Accepted: 25 July 2013

Published: 23 August 2013

\section{References}

1. Wolfe CD, Crichton SL, Heuschmann PU, McKevitt CJ, Toschke AM, Grieve $A P$, Rudd AG: Estimates of outcomes up to ten years after stroke: analysis from the prospective South London stroke register. PLoS Med 2011, 8(5):e1001033.

2. Morris PL, Robinson RG, Andrzejewski P, Samuels J, Price TR: Association of depression with 10-year post-stroke mortality. Am J Psychiatry 1993, 150:124-129.

3. Downhill JE Jr, Robinson RG: Longitudinal assessment of depression and cognitive impairment following stroke. J Nerv Ment Dis 1994, 182(8):425-431.

4. Paolucci S, Antonucci G, Pratesi L, Traballesi M, Grasso MG, Lubich S: Poststroke depression and its role in rehabilitation of inpatients. Arch Phys Med Rehabil 1999, 80(9):985-990.

5. Gainotti G, Antonucci G, Marra C, Paolucci S: Relation between depression after stroke, antidepressant therapy, and functional recovery. J Neurol Neurosurg Psychiatry 2001, 71(2):258-261.

6. Williams LS, Ghose SS, Swindle RW: Depression and other mental health diagnoses increase mortality risk after ischemic stroke. Am J Psychiatry 2004, 161(6):1090-1095.

7. Pohjasvaara T, Vataja R, Leppävuori A, Kaste M, Erkinjuntti T: Depression is an independent predictor of poor long-term functional outcome poststroke. Eur J Neurol 2001, 8(4):315-319.

8. Chemerinski E, Robinson RG, Kosier JT: Improved recovery in activities of daily living associated with remission of post-stroke depression. Stroke 2001, 32(1):113-117.

9. Loubinoux I, Kronenberg G, Endres M, Schumann-Bard P, Freret T, Filipkowski RK, Kaczmarek L, Popa-Wagner A: Post-stroke depression: mechanisms, translation and therapy. J Cell Mol Med 2012, 16(9):1961-1969.

10. Hackett ML, Yapa C, Parag V, Anderson CS: Frequency of depression after stroke: a systematic review of observational studies. Stroke 2005, 36(6):1330-1340.

11. Folstein MF, Maiberger R, McHugh PR: Mood disorder as a specific complication of stroke. J Neurol Neurosurg Psychiatry 1977, 40(10):1018-1020.

12. Alexopoulos GS, Meyers BS, Young RC, Campbell S, Silbersweig D, Charlson M: 'Vascular depression' hypothesis. Arch Gen Psychiatry 1997, 54(10):915-922.

13. Charidimou A, Werring DJ: Cerebral microbleeds and cognition in cerebrovascular disease: an update. J Neurol Sci 2012, 322(1-2):50-55.

14. Lim JS, Kwon HM: Risk of "silent stroke" in patients older than 60 years: risk assessment and clinical perspectives. Clin Interv Aging 2010, 5:239-251.

15. Sun MK, Alkon DL: Activation of protein kinase $C$ isozymes for the treatment of dementias. Adv Pharmacol 2012, 64:273-302.

16. Buga AM, Vintilescu R, Balseanu AT, Pop OT, Streba C, Toescu E, PopaWagner A: Repeated PTZ treatment at 25-day intervals leads to a highly efficient accumulation of doublecortin in the dorsal hippocampus of rats. PLoS One 2012, 7(6):e39302. 
17. Feigin VL, Lawes CMM, Bennett DA, Anderson CS: Stroke epidemiology: a review of populationbased studies of incidence, prevalence, and case-fatality in the late 20th century. THE LANCET Neurology 2003, 2:43-53.

18. Mishra NK, Diener HC, Lyden PD, Bluhmki E, Lees KR: Influence of age on outcome from Thrombolysis in Acute Stroke: a controlled comparison in patients from the Virtual International Stroke Trials Archive (VISTA). Stroke 2010, 41:2840-2848.

19. Wagner AP, Schmoll H, Badan I, Platt D, Kessler C: Brain plasticity: to what extent do aged animals retain the capacity to coordinate gene activity in response to acute challenges. Exp Gerontol 2000, 35(9-10):1211-1227.

20. Badan I, Buchhold B, Hamm A, Gratz M, Walker LC, Platt D, Kessler C, Popa-Wagner A: Accelerated glial reactivity to stroke in aged rats correlates with reduced functional recovery. J Cereb Blood Flow Metab 2003, 23(7):845-854.

21. Wang RY, Wang PSG, Yang YR: Effect of age in rats following middle cerebral artery occlusion. Gerontology 2003, 49:27-32.

22. Zhang L, Zhang RL, Wang Y, Zhang C, Zhang ZG, Meng H, Chopp M: Functional recovery in aged and young rats after embolic stroke: treatment with a phosphodiesterase type 5 inhibitor. Stroke 2005, 36:847-852

23. Won SJ, Xie L, Kim SH, Tang H, Wang Y, Mao X: Influence of age on the response to fibroblast growth factor- 2 treatment in a rat model of stroke. Brain Res 2006, 1123:237-244.

24. Chen Y, Sun FY: Age-related decrease of striatal neurogenesis is associated with apoptosis of neural precursors and newborn neurons in rat brain after ischemia. Brain Res 2007, 166:9-19.

25. DiNapoli VA, Huber JD, Houser K, Li X, Rosen CL: Early disruptions of the blood-brain barrier may contribute to exacerbated neuronal damage and prolonged functional recovery following stroke in aged rats. Neurobiol Aging 2008, 29:753-764

26. Badan I, Platt D, Kessler C, Popa-Wagner A: Temporal dynamics of degenerative and regenerative events associated with cerebral ischemia in aged rats. Gerontology 2003, 49(6):356-365.

27. Popa-Wagner A, Badan I, Walker L, Groppa S, Patrana N, Kessler C: Accelerated infarct development, cytogenesis and apoptosis following transient cerebral ischemia in aged rats. Acta Neuropathol 2007, 113(3):277-293.

28. Karki K, Knight RA, Shen LH, Kapke A, Lu M, Li Y, Chopp M: Chronic brain tissue remodeling after stroke in rats: a 1-year multiparametric magnetic resonance imaging study. Brain Res 2010, 1160:168-176.

29. Brenneman M, Sharma S, Harting M, Strong R, Cox CHS Jr, Aronowski J, Grotta JC, Savitz SI: Autologous bone marrow mononuclear sells enhance recovery after acute ischemic stroke in young and middle-aged rats. J Cereb Blood Flow Metab 2010, 30:140-149.

30. Canese R, Fortuna S, Lorenzini P, Podo F, Michalek H: Transient global brain ischemia in young and aged rats: differences in severity and progression, but not localization, of lesions evaluated by magnetic resonance imaging. Magn Res Materials in Physics, Biol Med 1998, 7:28-34.

31. Canese R, Lorenzini P, Fortuna S, Volpe MT, Giannini M, Podo F, Michalek H: Age-dependent MRI-detected lesions at early stages of transient global ischemia in rat brain. MAGMA 2004, 17(3-6):109-116.

32. Markus TM, Tsai SY, Bollnow MR, Farrer RG, O'Brien TE, Kindler-Baumann DR, Rausch M, Rudin M, Wiessner C, Mir AK, Schwab ME, Kartje GL: Recovery and brain reorganization after stroke in adult and aged rats. Ann Neurol 2005, 58:950-953.

33. Macri MA, D'Alessandro N, Di Giulio C, Di lorio P, Di Luzio S, Giuliani P, Esposito E, Pokoski M: Region-specific effects on brain metabolites of hypoxia and hyperoxia overlaid on cerebral ischemia in young and old rats: a quantitative proton magnetic resonance spectroscopy study. J Biomed Science 2010, 17:14

34. Joseph C, Buga AM, Vintilescu R, Balseanu AT, Moldovan M, Junker $H$, Walker L, Lotze M, Popa-Wagner A: Prolonged gaseous hypothermia prevents the upregulation of phagocytosis-specific protein annexin 1 and causes low-amplitude EEG activity in the aged rat brain after cerebral ischemia. J Cereb Blood Flow Metab 2012, 32(8):1632-1642.

35. Willner $P$, Mitchell PJ: The validity of animal models of predisposition to depression. Behav Pharmacol 2002, 13:169-188.

36. Vollmayr B, Mahlstedt MM, Henn FA: Neurogenesis and depression: what animal models tell us about the link. Eur Arch Psychiatry Clin Neurosci 2007, 257:300-303.
37. Hasler G, Drevets W, Manji H, Charney D: Discovering endophenotypes for major depression. Neuropsychopharmacology 2004, 29:1765-1781.

38. Porsolt RD, Bertin A, Jalfre M: Behavioral despair in mice: a primary screening test for antidepressants. Arch Int Pharmacodyn Ther 1977, 229:327-336.

39. Steru $L$, Chermat $R$, Thierry $B$, Simon P: The tail suspension test: a new method for screening antidepressants in mice. Psychopharmacology (Berl) 1985, 85:367-370

40. Malatynska E, Steinbusch HW, Redkozubova O, Bolkunov A, Kubatiev A, Yeritsyan NB, Vignisse J, Bachurin S, Strekalova T: Anhedonic-like traits and lack of affective deficits in 18-month-old C57BL/6mice: implications for modeling elderly depression. Exp Gerontol 2012, 47(8):552-564.

41. Cryan JF, Mombereau C, Vassout A: The tail suspension test as a model for assessing antidepressant activity: review of pharmacological and genetic studies in mice. Neurosci Biobehav Rev 2005, 29:571-625.

42. Szkutnik-Fiedler D, Kus K, Balcerkiewicz M, Grześkowiak E, Nowakowska E, Burda K, Ratajczak P, Sadowski C: Concomitant use of tramadol and venlafaxine - evaluation of antidepressant-like activity and other behavioral effects in rats. Pharmacol Rep 2012, 64(6):1350-1358.

43. Willner P, Muscat R, Papp M: Chronic mild stress-induced anhedonia: a realistic animal model of depression. Neurosci Biobehav Rev 1992, 16:525-534.

44. Harden MT, Smith SE, Niehoff JA, McCurdy CR, Taylor GT: Antidepressive effects of the opioid receptor agonist salvinorin $A$ in a rat model of anhedonia. Behav Pharmacol 2012, 23(7):710-715.

45. Dalm S, De Kloet ER, Oitzl MS: Post-training reward partially restores chronic stress induced effects in mice. PLoS One 2012, 7(6):e39033. doi:10.1371/journal.pone.0039033.

46. Craft TK, DeVries AC: Role of IL-1 in post-stroke depressive-like behavior in mice. Biol Psychiatry 2006, 60:812-818.

47. Robinson RG, Starr LB, Lipsey JR, Rao K, Price TR: A two-year longitudinal study of post-stroke mood disorders: dynamic changes in associated variables over the first six months of follow-up. Stroke 1984, 15:510-517.

48. Bhogal SK, Teasell R, Foley N, Speechley M: Lesion Location and Poststroke Depression : systematic review of the methodological limitations in the literature. Stroke 2004, 35:794-802.

49. Robinson RG, Spaletta G: Poststroke depression: a review. Can J Psychiatry 2010, 55(suppl 6):341-349.

50. Kim JT, Park MS, Yoon GJ, Jung HJ, Choi KH, Nam TS, Lee SH, Choi SM, Kim BC, Kim MK, Cho K: White matter hyperintensity as a factor associated with delayed mood disorders in patients with acute ischemic stroke. Eur Neurol 2011, 66(suppl6):343-349.

51. Robinson RG: The clinical neuropsychiatry of stroke. 2. Cambridge (MA): Cambridge University Press; 2006.

52. Narushima K, Kosier JT, Robinson RG: A reappraisal of poststroke depression, intra- and interhemispheric lesion location using metaanalysis. J Neuropsychiatry Clin Neurosc 2003, 15(suppl4):422-430.

53. Kohen R, Cain KC, Mitchell PH, Becker K, Buzaitis A, Millard SP, Navaja GP Teri L, Tirschwell D, Veith R: Association of serotonin transporter gene polymorphisms with poststroke depression. Arch Gen Psychiatry 2008, 65(suppl11):1296-1302

54. Sinyor D, Amato P, Kaloupek DG, Becker R, Goldenberg M, Coopersmith H: Post-stroke depression: relationships to functional impairment, coping strategies, and rehabilitation outcome. Stroke 1986, 17(6):1102-1107.

55. Rashid N, Clarke C, Rogish M: Post-stroke depression and expressed emotion. Brain Inj 2013, 27(2):223-238.

56. Stuller KA, Jarrett $B$, DeVries AC: Stress and social isolation increase vulnerability to stroke. Exp Neurol 2012, 233(1):33-39.

57. Schepers V, Post M, Vlsser-Meily A, van de Port I, Akhmouch M, Lindeman E: Prediction of depressive syptoms up to three years post-stroke. J Rehabil Med 2009, 41:930-935.

58. Åström M, Adolfsson R, Asplund K: Major depression in stroke patients. Stroke 1993, 24:976-982.

59. Deng W, Aimone JB, Gage FH: New neurons and new memories: how does adult hippocampal neurogenesis affect learning and memory? Nature Reviews 2010, 11:339-350.

60. Williamson LL, Bilbo SD: Chemokines and the hippocampus: a new perspective on hippocampal plasticity and vulnerability. Brain Behav Immun 2013, 30:186-194.

61. Lee S, Jeong J, Kwak Y, Park SK: Depression research: where are we now? Mol Brain 2010, 3:8. 
62. Sakata K, Mastin JR, Duke SM, Vail MG, Overacre AE, Dong BE, Jha S: Effects of antidepressant treatment on mice lacking brain-derived neurotrophic factor expression through promoter IV. Eur J Neurosci 2013, 37(11):1863-1874.

63. Kato $M$, Iwata $H$, Okamoto $M$, Ishii $T$, Narita $H$ : Focal cerebral ischemiainduced escape deficit in rats is ameliorated by a reversible inhibitor of monoamine oxidase-a: implications for a novel animal model of poststroke depression. Biol Pharm Bull 2000, 23:406-410.

64. Jaholkowski P, Kiryk A, Jedynak P, Ben Abdallah NM, Knapska E, Kowalczyk A, Piechal A, Blecharz-Klin K, Figiel I, Lioudyno V, Widy-Tyszkiewicz E, Wilczynski GM, Lipp HP, Kaczmarek L, Filipkowski RK: New hippocampal neurons are not obligatory for memory formation; cyclin D2 knockout mice with no adult brain neurogenesis show learning. Learn Mem 2009, 16(7):439-451.

65. Jedynak P, Jaholkowski P, Wozniak G, Sandi C, Kaczmarek L, Filipkowski RK: Lack of cyclin D2 impairing adult brain neurogenesis alters hippocampal-dependent behavioral tasks without reducing learning ability. Behav Brain Res 2012, 227(1):159-166.

66. Seib DR, Corsini NS, Ellwanger K, Plaas C, Mateos A, Pitzer C, Niehrs C, Celikel T, Martin-Villalba A: Loss of dickkopf-1 restores neurogenesis in old age and counteracts cognitive decline. Cell Stem 2013, 12(2):204-214.

67. Meier C, Anastasiadou S, Knöll B: Ephrin-A5 Suppresses Neurotrophin Evoked Neuronal Motility, ERK Activation and Gene Expression. PLoS One 2011, 6(10):e26089. doi:10.1371/journal.pone.0026089.

68. Bi C, Yue X, Zhou R, Plummer MR: EphA activation overrides the presynaptic actions of BDNF. J Neurophysio/ 2011, 105(5):2364-2374.

69. Driscoll I, Martin B, An Y, Maudsley S, Ferrucci L, Mattson MP, Resnick SM: Plasma BDNF is associated with age-related white matter atrophy but not with cognitive function in older, non-demented adults. PLoS One 2012, 7(4):e35217.

70. Cui X, Chopp M, Shehadah A, Zacharek A, Kuzmin-Nichols N, Sanberg CD, Dai J, Zhang C, Ueno Y, Roberts C, Chen J: Therapeutic benefit of treatment of stroke with simvastatin and human umbilical cord blood cells: neurogenesis, synaptic plasticity, and axon growth. Cell Transplant 2012, 21(5):845-856.

71. Couillard-Despres S, Vreys R, Aigner L, Van der Linden A: In vivo monitoring of adult neurogenesis in health and disease. Front Neurosci 2011, 5:67.

72. Huston JP, Schulz D, Topic B: Toward an animal model of extinctioninduced despair: focus on aging and physiological indices. J Neural Transm 2009, 116(8):1029-1036.

73. Baltan S: Ischemic injury to white matter: an age-dependent process. Neuroscientist 2009, 15(2):126-133.

74. Wang SH, Zhang ZJ, Guo YJ, Sui YX, Sun Y: Involvement of serotonin neurotransmission in hippocampal neurogenesis and behavioral responses in a rat model of post-stroke depression. Pharmacol Biochem Behav 2010, 95:129-137.

75. Kronenberg G, Balkaya M, Prinz V, Gertz K, Ji S, Kirste I, Heuser I, Kampmann B, Hellmann-Regen J, Gass P, Sohr R, Hellweg R, Waeber C, Juckel G, Hörtnagl H, Stumm R, Endres M: Exofocal dopaminergic degeneration as antidepressant target in mouse model of post-stroke depression. Biol Psychiatry 2012, 72(4):273-281.

76. Perera TD, Dwork AJ, Keegan KA, Thirumangalakudi L, Lipira CM, Joyce $N_{\text {, }}$ Lange C, Higley JD, Rosoklija G, Hen R, Sackeim HA, Coplan JD: Necessity of hippocampal neurogenesis for the therapeutic action of antidepressants in adult nonhuman primates. PLoS One 2011, 6(4):e17600.

77. Luo CX, Jiang J, Zhou QG, Zhu XJ, Wang W, Zhang ZJ, Han X, Zhu DY: Voluntary exercise-induced neurogenesis in the postischemic dentate gyrus is associated with spatial memory recovery from stroke. J Neurosci Res 2007, 85:1637-1646.

78. Rothman SM, Griffioen KJ, Wan R, Mattson MPL: Brain-derived neurotrophic factor as a regulator of systemic and brain energy metabolism and cardiovascular health. Ann N Y Acad Sci 2012, 1264(1):49-63.

79. Kang HJ, Voleti B, Hajszan T, Rajkowska G, Stockmeier CA, Licznerski P, Lepack A, Majik MS, Jeong LS, Banasr M, Son H, Duman RS: Decreased expression of synapse-related genes and loss of synapses in major depressive disorder. Nat Med 2012, 18(9):1413-1417.

80. Urigüen L, Arteta D, Díez-Alarcia R, Ferrer-Alcón M, Díaz A, Pazos A, Meana $\mathrm{JJ}$ : Gene expression patterns in brain cortex of three different animal models of depression. Genes Brain Behav 2008, 7:649-658.

81. Ducruet AF, Zacharia BE, Sosunov SA, Gigante PR, Yeh ML, Gorski JW, Otten ML, Hwang RY, DeRosa PA, Hickman ZL, Sergot P, Connolly ES Jr: Complement inhibition promotes endogenous neurogenesis and sustained anti-inflammatory neuroprotection following reperfused stroke. PLoS One 2012, 7(6):e38664.

82. Smith RM, Papp AC, Webb A, Ruble CL, Munsie LM, Nisenbaum LK, Kleinman JE, Lipska BK, Sadee W: Multiple Regulatory Variants Modulate Expression of 5-Hydroxytryptamine 2A Receptors in Human Cortex. Biol Psychiatry 2012, 73(6):546-554

83. Lohoff FW, Aquino TD, Narasimhan S, Multani PK, Etemad B, Rickels K: Serotonin receptor $2 A$ (HTR2A) gene polymorphism predicts treatment response to venlafaxine $X R$ in generalized anxiety disorder. Pharmacogenomics J 2013, 13(1):21-26.

84. Hagemeyer N, Goebbels S, Papiol S, Kästner A, Hofer S, Begemann M, Gerwig UC, Boretius S, Wieser GL, Ronnenberg A, Gurvich A, Heckers SH, Frahm J, Nave KA, Ehrenreich $\mathrm{H}$ : A myelin gene causative of a catatoniadepression syndrome upon aging. EMBO Mol Med 2012, 4(6):528-539.

85. Yutsudo N, Kamada T, Kajitani K, Nomaru H, Katogi A, Ohnishi YH, Ohnishi YN, Takase Kl, Sakumi K, Shigeto H, Nakabeppu Y: fosB-Null Mice Display Impaired Adult Hippocampal Neurogenesis and Spontaneous Epilepsy with Depressive Behavior. Neuropsychopharmacology 2012, 38(5):895-906.

86. Herdegen T, Leah JD: Inducible and constitutive transcription factors in the mammalian nervous system: control of gene expression by Jun, Fos and Krox, and CREB/ATF proteins. Brain Res Rev 1998, 28(3):370-490.

87. Kindy MS, Carney JP, Dempsey RJ, Carney JM: Ischemic induction of protooncogene expression in gerbil brain. J Mol Neurosci 1991, 2(4):217-228.

88. Lee N, Batt MK, Cronier BA, Jackson MC, Bruno Garza JL, Trinh DS, Mason CO, Spearry RP, Bhattacharya S, Robitz R, Nakafuku M, Maclennan AJ: Ciliary neurotrophic factor receptor regulation of adult forebrain neurogenesis J Neurosci 2013, 33(3):1241-1258.

89. Kang SS, Keasey MP, Arnold SA, Reid R, Geralds J, Hagg T: Endogenous CNTF mediates stroke-induced adult CNS neurogenesis in mice. Neurobiol Dis 2012, 49C:68-78.

90. Quiroz JA, Gould TD, Manji HK: Molecular effects of lithiu. Mol Interv 2004 4:259-272

91. Roybal K, Theobold D, Graham A, DiNieri JA, Russo SJ, Krishnan V, Chakravarty S, Peevey J, Oehrlein N, Birnbaum S, Vitaterna MH, Orsulak P, Takahashi JS, Nestler EJ, Carlezon WA Jr, McClung CA: Mania-like behavior induced by disruption of CLOCK. Proc Natl Acad Sci USA 2007, 104:6406-6411.

92. Partonen T, Treutlein J, Alpman A, Frank J, Johansson C, Depner M, Aron L, Rietschel M, Wellek S, Soronen P, Paunio T, Koch A, Chen P, Lathrop M, Adolfsson R, Persson ML, Kasper S, Schalling M, Peltonen L, Schumann G: Three circadian clock genes Per2, Arntl, and Npas2 contribute to winter depression. Ann Med 2007, 39(suppl3):229-238.

93. Ebisawa T: Analysis of the molecular pathophysiology of sleep disorders relevant to a disturbed biological clock. Mol Genet Genomics 2013, 288:185-193.

94. Partonen T: Clock gene variants in mood and anxiety disorders. J Neural Transm 2012, 119(suppl 10):1133-1145.

95. Ramos-Cejudo J, Gutiérrez-Fernández M, Rodríguez-Frutos B, Alcaide ME, Sánchez-Cabo F, Dopazo A, Díez-Tejedor E: Spatial and temporal gene expression differences in core and Periinfarct areas in experimental stroke: a microarray analysis. PLoS One 2012, 7(12):e52121.

96. Duncan MJ, Smith JT, Franklin KM, Beckett TL, Murphy MP, St Clair DK Donohue KD, Striz M, O'Hara BF: Effects of aging and genotype on circadian rhythms, sleep, and clock gene expression in APPXPS1 knockin mice, a model for Alzheimer's disease. Exp Neurol 2012, 236:249-258.

97. Nievergelt CM, Kripke DF, Barrett TB, Burg E, Remick RA, Sadovnick AD, McElroy SL, Keck PE Jr, Schork NJ, Kelsoe JR: Suggestive evidence for association of the circadian genes PERIOD3 and ARNTL with bipolar disorder. Am J Med Genet B Neuropsychiatr Genet 2006, 141:234-241.

98. Viola AU, Chellappa SL, Archer SN, Pugin F, Götz T, Dijk DJ, Cajochen C: Interindividual differences in circadian rhythmicity and sleep homeostasis in older people: effect of a PER3 polymorphism. Neurobiol Aging 2012, 33(suppl 5):1010.e17-1010.e27.

99. Schmidt C, Peigneux P, Cajochen C: Age-related changes in sleep and circadian rhythms: impact on cognitive performance and underlying neuroanatomical networks. Front Neurol 2012, 3:118.

100. Hayden EP, Dougherty LR, Maloney B, Olino TM, Sheikh H, Durbin CE, Nurnberger JI Jr, Lahiri DK, Klein DN: Early-emerging cognitive vulnerability to depression and the serotonin transporter promoter region polymorphism. J Affect Disord 2008, 107(suppl 1-3):227-230. 
101. Liang SW, Dunckley T, Thomas GB, Grover A, Mastroeni D, Ramsey K, Casell RJ, Kukull WA, McKeel D, Morris JC, Hulette CM, Schmechel D, Reiman EM, Rogers J, Stephan DA: Altered neuronal gene expression in brain regions differentially affected by Alzheimer's disease: a reference data set. Physiol Genomics 2008, 33(2):240-256.

102. Durham LK, Webb SM, Milos PM, Clary CM, Seymour AB: The serotonin transporter polymorphism, 5HTTLPR, is associated with a faster response time to sertraline in an elderly population with major depressive disorder. Psychopharmacology (Berl) 2004, 174(4):525-529.

103. Pearson-Fuhrhop KM, Cramer SC: Genetic influences on neural plasticity. PM R 2010, 2(12 Suppl 2):S227-740.

104. DeGracia DJ: Towards a dynamical network view of brain ischemia and reperfusion: Part II: a post-ischemic neuronal state space. J Exp Stroke Transl Med 2010, 3(1):72-89.

105. Coogan AN, Thome J: Chronotherapeutics and psychiatry: setting the clock to relieve the symptoms. World J Biol Psychiatry 2011, 12(suppl 1):40-43.

106. Gorwood P: Restoring circadian rhythms: a new way to successfully manage depression. J Psychopharmacol 2010, 24(2 Suppl):15-19.

107. Dallaspezia S, Benedetti F: Melatonin, circadian rhythms, and the clock genes in bipolar disorder. Curr Psychiatry Rep 2009, 11(6):488-493.

108. Monteleone P, Martiadis V, Maj M: Circadian rhythms and treatment implications in depression. Prog Neuropsychopharmacol Biol Psychiatry 2011, 35(7):1569-1574.

109. Mendlewicz J: Disruption of the circadian timing systems: molecular mechanisms in mood disorders. CNS Drugs 2009, 23(Suppl 2):15-26.

110. Kasper S, Hajak G, Wulff K, Hoogendijk WJ, Montejo AL, Smeraldi E, Rybakowski JK, Quera-Salva MA, Wirz-Justice AM, Picarel-Blanchot F, Baylé FJ: Efficacy of the novel antidepressant agomelatine on the circadian restactivity cycle and depressive and anxiety symptoms in patients with major depressive disorder: a randomized, double-blind comparison with sertraline. J Clin Psychiatry 2010, 71(2):109-120.

111. Yang S, Van Dongen HP, Wang K, Berrettini W, Bućan M: Assessment of circadian function in fibroblasts of patients with bipolar disorder. Mol Psychiatry 2009, 14(2):143-155.

112. Fornaro M, McCarthy MJ, De Berardis D, De Pasquale C, Tabaton M, Martino M, Colicchio S, Cattaneo Cl, D'Angelo E, Fornaro P: Adjunctive agomelatine therapy in the treatment of acute bipolar II depression: a preliminary open label study. Neuropsychiatr Dis Treat 2013, 9:243-251.

113. Challet E: Minireview: entrainment of the suprachiasmatic clockwork in diurnal and nocturnal mammals. Endocrinology 2007, 148(12):5648-5655.

114. Cuesta M, Clesse D, Pévet $P$, Challet E: From daily behavior to hormonal and neurotransmitters rhythms: comparison between diurnal and nocturnal rat species. Horm Behav 2009, 55(2):338-347.

115. Smale L, Nunez AA, Schwartz MD: Rhythms in a diurnal brain. Biol Rhythm Res 2008, 39:305-318.

116. Cohen R, Smale L, Kronfeld-Schor N: Masking and temporal niche switches in spiny mice. J Biol Rhythms 2010, 25(1):47-52.

117. Hagenauer $\mathrm{MH}$, Lee TM: Circadian organization of the diurnal Caviomorph rodent, Octodon degus. Biol Rhythms Res 2008, 39:269-289.

118. Kronfeld-Schor N, Einat H: Circadian rhythms and depression: human psychopathology and animal models. Neuropharmacology 2012, 62(1):101-114.

119. Weldemichael DA, Grossberg GT: Circadian rhythm disturbances in patients with Alzheimer's disease: a review. Int J Alzheimers Dis 2010 doi: 10.4061/2010/716453.

120. Oosterman JM, Van Someren EJ, Vogels RL, Van Harten B, Scherder EJ: Fragmentation of the restactivity rhythm correlates with age-related cognitive deficits. J Sleep Res 2009, 18(1):129.

121. Hermann DM, Bassetti CL: Sleep-related breathing and sleep-wake disturbances in ischemic stroke. Neurology 2009, 73(sppl16):1313-1322.

122. Ramar K, Surani S: The relationship between sleep disorders and stroke. Postgrad Med 2010, 122(suppl6):145-153.

123. Oxenkrug G, Ratner R: N-acetylserotonin and aging-associated cognitive impairment and depression. Aging Dis 2012, 3(4):330-338.

124. Jang SW, Liu X, Pradoldej S, Tosini G, Chang Q, luvone PM, Ye K: Nacetylserotonin activates TrkB receptor in a circadian rhythm. Proc Natl Acad Sci USA 2010, 107(8):3876-3881.

125. Bunney BG, Bunney WE: Mechanisms of. Clock Genes and Circadian Rhythms. Biol Psychiatry.: Rapid Antidepressant Effects of Sleep Deprivation Therapy; 2012
126. Thome J, Coogan AN, Woods AG, Darie CC, Häßler F: CLOCK genes and Circadian rhythmicity in Alzheimer disease. J Ageing Res 2011, 2011:383091. doi:10.4061/2011/383091.

127. Skolnick P, Popik P, Janowsky A, Beer B, Lippa AS: Antidepressant-like actions of DOV 21,947: a "triple" reuptake inhibitor. Eur J Pharmacol 2003, 461(2-3):99-104.

128. Lucki I, O'Leary OF: Distinguishing roles for norepinephrine and serotonin in the behavioral effects of antidepressant drugs. J Clin Psychiatry 2004, 65(Suppl 4):11-24.

129. Noonan K, Carey LM, Crewther SG: Meta-analyses Indicate Associations between Neuroendocrine Activation, Deactivation in Neurotrophic and Neuroimaging Markers in Depression after Stroke. J Stroke Cerebrovasc Dis 2012. doi:10.1016/j.jstrokecerebrovasdis.2012.09.008.

130. Salter K, Foley N, Teasell R: Social support interventions and mood status post stroke: a review. Int J Nurs Stud 2010, 47(5):616-625.

131. Narushima K, Robinson RG: The effect of early versus late antidepressant treatment on physical impairment associated with post-stroke depression: is there a time-related therapeutic window? J Nerv Ment Dis 2003, 191(10):645-652.

132. Narushima K, Paradiso S, Moser DJ, Jorge R, Robinson RG: Effect of antidepressant therapy on executive function after stroke. $\mathrm{Br} J$ Psychiatry 2007, 190:260-265.

133. Acler M, Robol E, Fiaschi A, Manganotti P: A double blind placebo RCT to investigate the effects of serotonergic modulation on brain excitability and motor recovery in stroke patients. J Neurol 2009, 256(7):1152-1158.

134. Jorge RE, Acion L, Moser D, Adams HP Jr, Robinson RG: Escitalopram and enhancement of cognitive recovery following stroke. Arch Gen Psychiatry 2010, 67:187-196.

135. Pariente J, Loubinoux I, Carel C, Albucher JF, Leger A, Manelfe C, Rascol O, Chollet F: Fluoxetine modulates motor performance and cerebral activation of patients recovering from stroke. Ann Neurol 2001, 50(6):718-729

136. Chollet F, Tardy J, Albucher JF, Thalamas C, Berard E, Lamy C, Bejot $Y$, Deltour S, Jaillard A, Niclot P, Guillon B, Moulin T, Marque P, Pariente J, Arnaud $C$, Loubinoux I: Fluoxetine for motor recovery after acute ischaemic stroke (FLAME): a randomised placebo-controlled trial. Lancet Neurol 2011, 10(2):123-130.

doi:10.1186/2049-9256-1-14

Cite this article as: Cojocaru et al.: Post-stroke depression and the aging brain. Journal of Molecular Psychiatry 2013 1:14

\section{Submit your next manuscript to BioMed Central and take full advantage of:}

- Convenient online submission

- Thorough peer review

- No space constraints or color figure charges

- Immediate publication on acceptance

- Inclusion in PubMed, CAS, Scopus and Google Scholar

- Research which is freely available for redistribution 